\title{
Reduced networks governing the fractional ionisation in interstellar molecular clouds
}

\author{
J. G. L. Rae ${ }^{1}$, N. Bell ${ }^{2}$, T. W. Hartquist ${ }^{1}$, M. J. Pilling ${ }^{2}$, and D. P. Ruffle ${ }^{2}$ \\ 1 Department of Physics and Astronomy, University of Leeds, Leeds LS2 9JT, UK \\ 2 School of Chemistry, University of Leeds, Leeds LS2 9JT, UK
}

Received 7 November 2001 / Accepted 6 December 2001

\begin{abstract}
We have used objective techniques to identify, from a huge chemical network, reduced networks that accurately describe the chemistry governing the fractional ionisation in interstellar molecular clouds under a wide variety of conditions.
\end{abstract}

Key words. astrochemistry - stars: formation - ISM: abundances - ISM: clouds - ISM: molecules ISM: magnetic fields

\section{Introduction}

The translucent nature of many dense cores in which star formation occurs necessitates the inclusion of photoabsorption processes in the calculation of the fractional ionisation in studies of collapse regulated by ambipolar diffusion (e.g. McKee 1989; Ciolek \& Mouschovias 1995). Ion-neutral friction damps hydromagnetic waves (Kulsrud \& Pearce 1969). Thus, the fractional ionisation may play important roles in determining in what regions of dense cores and of more tenuous clumps within Giant Molecular Clouds (e.g. Bertoldi \& McKee 1992; Williams et al. 1995) hydromagnetic waves can propagate with little dissipation (e.g. Mouschovias 1991; Myers \& Lazarian 1998; Coker et al. 2000).

Reliable simple analytic expressions have been derived for the calculation of the fractional ionisation in dark regions (Oppenheimer \& Dalgarno 1974; Elmegreen 1979). McKee (1989) gave an analytic treatment of the fractional ionisation in regions in which $\mathrm{C}^{+}$is not an important ion but ionisation of metals, such as magnesium and sulphur, by photons of the diffuse interstellar background radiation field, is significant. Ciolek \& Mouschovias (1995) isolated a small chemical network that gives results for the fractional ionisation that are appropriate for dense regions of moderate and high extinction, the dynamics of which were the main focus of their study.

Though very useful in many situations, none of the treatments mentioned in the previous paragraph produces

Send offprint requests to: J. G. L. Rae,

e-mail: jglr@ast.leeds.ac.uk completely reliable results under all conditions likely to be of interest. For instance, in clumps identified in CO maps of the Rosette Molecular Cloud (Williams et al. 1995) and in similar clumps in other Giant Molecular Clouds (e.g. Bertoldi \& McKee 1992) much of the material is at physical conditions that differ from those for which the simple treatments of fractional ionisation are accurate. However, computational limitations preclude the inclusion of an extensive chemistry like that employed by Ruffle et al. (1998) in a multidimensional fully coupled dynamical and chemical model of the collapse of a magnetised clump or dense core.

Consequently, we have used objective techniques developed in other contexts by chemical kineticists (Tomlin et al. 1992, 1997) to select a network of reduced size for the calculation of the fractional ionisation under a very broad range of physical conditions. These techniques have been applied previously to the chemistry of $\mathrm{CO}$ in interstellar clouds (Ruffle et al. 2002). In Sect. 2 we comment on the networks with which we started and summarise briefly the principles on which the reduction techniques are based. Section 3 contains a description of how we have applied the reduction techniques to the identification of a reliable network for the calculation of the fractional ionisation. Reduced networks giving valid results are presented for a variety of situations in Sect. 4; the possibility of different selective depletions is addressed. Combination of reduced networks considered in Sect. 4 is addressed in Sect. 5. In Sect. 6 we identify those species that can be assumed to be in "quasi-steady state" as several collapse scenarios occur. In that section we also present and compare results 
Table 1. Elemental abundances.

\begin{tabular}{|l|l|l|}
\hline Element & $\begin{array}{l}\text { Low-metal } \\
\text { abundances }\end{array}$ & $\begin{array}{l}\text { High-metal } \\
\text { abundances }\end{array}$ \\
\hline $\mathrm{He}$ & $7 \times 10^{-2}$ & $7 \times 10^{-2}$ \\
$\mathrm{O}$ & $2 \times 10^{-4}$ & $2 \times 10^{-4}$ \\
$\mathrm{C}$ & $1 \times 10^{-4}$ & $1 \times 10^{-4}$ \\
$\mathrm{~N}$ & $2 \times 10^{-5}$ & $2 \times 10^{-5}$ \\
$\mathrm{~S}$ & $2 \times 10^{-8}$ & $6 \times 10^{-6}$ \\
$\mathrm{Na}$ & $2 \times 10^{-8}$ & $1 \times 10^{-6}$ \\
\hline
\end{tabular}

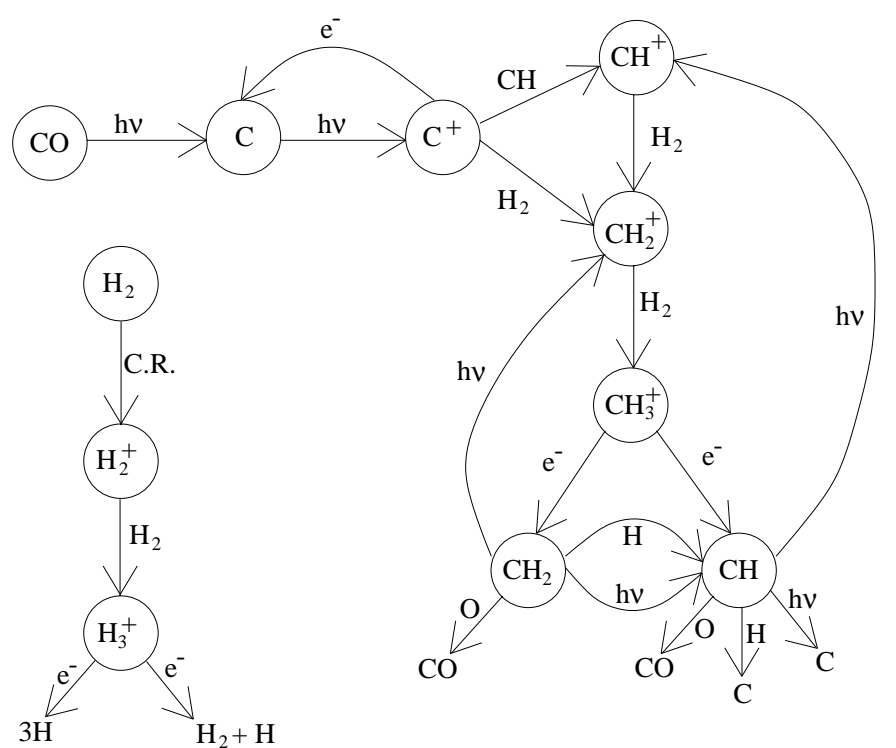

Fig. 1. Reduced network for $n_{\mathrm{H}}=10^{3} \mathrm{~cm}^{-3}, A_{\mathrm{V}}=1$, and low-metal abundances.

for the values of the fractional ionisation calculated with different networks for these collapse scenarios. Section 7 is a short summary.

\section{The "full" and "large" networks and the basic principles of the network reduction}

We began with two networks which we designate the "full" and "large" networks. The full network incorporates 218 species and 2747 reactions, while for the large network the numbers are 79 and 1026 respectively. The full network includes reactions involving elemental hydrogen, helium, oxygen, carbon, nitrogen, sulphur, and sodium. The inclusion of other low ionisation potential elements such as silicon and magnesium would cause little effect on the chemistry as long as the sum of the fractional abundances of such elements and of sodium is kept constant. The large network excludes elemental nitrogen and most species containing more than two nuclei more massive than hydrogen. In the large network, (i) reactions of $\mathrm{C}^{+}$with $\mathrm{OH}, \mathrm{H}_{2} \mathrm{O}$ and $\mathrm{O}_{2}$ were assumed to produce $\mathrm{HCO}^{+}$directly rather than the intermediate species such as $\mathrm{CO}^{+}$; (ii) the reactions of $\mathrm{H}^{+}$and $\mathrm{C}^{+}$with $\mathrm{O}_{2}$ were assumed to generate $\mathrm{O}$
Table 2. Largest values of $\log _{10} B_{i}$ for the $n_{\mathrm{H}}=10^{3} \mathrm{~cm}^{-3}$, $A_{\mathrm{V}}=1$, low-metal case.

\begin{tabular}{|l|l|}
\hline$i$ & $\log _{10} B_{i}$ \\
\hline $\mathrm{e}^{-}$ & 0.79 \\
$\mathrm{C}^{+}$ & 0.50 \\
$\mathrm{C}$ & 0.46 \\
$\mathrm{CH}_{3}^{+}$ & 0.41 \\
$\mathrm{CH}$ & 0.40 \\
$\mathrm{CH}_{2}^{+}$ & 0.32 \\
$\mathrm{H}_{2}^{+}$ & 0.30 \\
$\mathrm{CO}$ & 0.25 \\
$\mathrm{O}$ & 0.11 \\
$\mathrm{CH}_{2}$ & 0.04 \\
$\mathrm{CH}^{+}$ & 0.01 \\
$\mathrm{H}_{3}^{+}$ & 0.01 \\
$\mathrm{H}$ & -0.55 \\
$\mathrm{He}^{+}$ & -1.72 \\
$\mathrm{C}_{2}$ & -1.93 \\
$\mathrm{C}_{2} \mathrm{H}$ & -3.05 \\
$\mathrm{C}_{2}^{+}$ & -3.24 \\
$\mathrm{OH}^{+}$ & -4.92 \\
$\mathrm{H}^{+}$ & -5.03 \\
\hline
\end{tabular}

and $\mathrm{OH}^{+}$directly rather than the intermediate species $\mathrm{O}_{2}^{+}$ and $\mathrm{O}^{+}$; and (iii) cosmic ray induced ionisation of $\mathrm{O}$ was taken to produce $\mathrm{OH}^{+}$directly rather than $\mathrm{O}^{+}$.

The rates of gas phase reactions were taken mostly from the 1995 UMIST database (Millar et al. 1997). With two exceptions all modifications of rates and rate coefficients were identical to those made by Ruffle et al. (1998). One exception concerns the CO photodissociation rate which we took to have the depth dependence adopted by Coker et al. (2000). We also used different $\mathrm{H}_{3}^{+}+\mathrm{e}^{-} \rightarrow \mathrm{H}_{2}+\mathrm{H}$ and $\mathrm{H}_{3}^{+}+\mathrm{e}^{-} \rightarrow 3 \mathrm{H}$ rate coefficients; the values of $3.05 \times 10^{-8} \mathrm{~cm}^{-3} \mathrm{~s}^{-1}\left(\frac{T}{300 \mathrm{~K}}\right)^{-0.65}$ and $8.25 \times 10^{-8} \mathrm{~cm}^{-3} \mathrm{~s}^{-1}\left(\frac{T}{300 \mathrm{~K}}\right)^{-0.65}$ that we took are in harmony with the experimental results obtained by Larsson et al. (1993), Sundström et al. (1994) and Datz et al. (1995). The assumed external radiation field corresponds to a choice of unity for the appropriate normalisation factor in the UMIST database. The cosmic ray induced ionisation rate was set to $1.3 \times 10^{-17} \mathrm{~s}^{-1}$. The treatment of the neutralisation of charged species and the hydrogenation of unsaturated species on grain surfaces is as used by Ruffle et al. (1998).

The principles of the network reduction are described more fully by Tomlin et al. (1992, 1997). The code employed is called KINALC (available at http://www . chem. leeds . ac. uk/Combustion/kinalc.htm). We designate the number density of species $i$ by $n(i)$, the net production rate per unit time per unit volume of species $j$ as $f_{j}$ and the larger of the formation rate per 


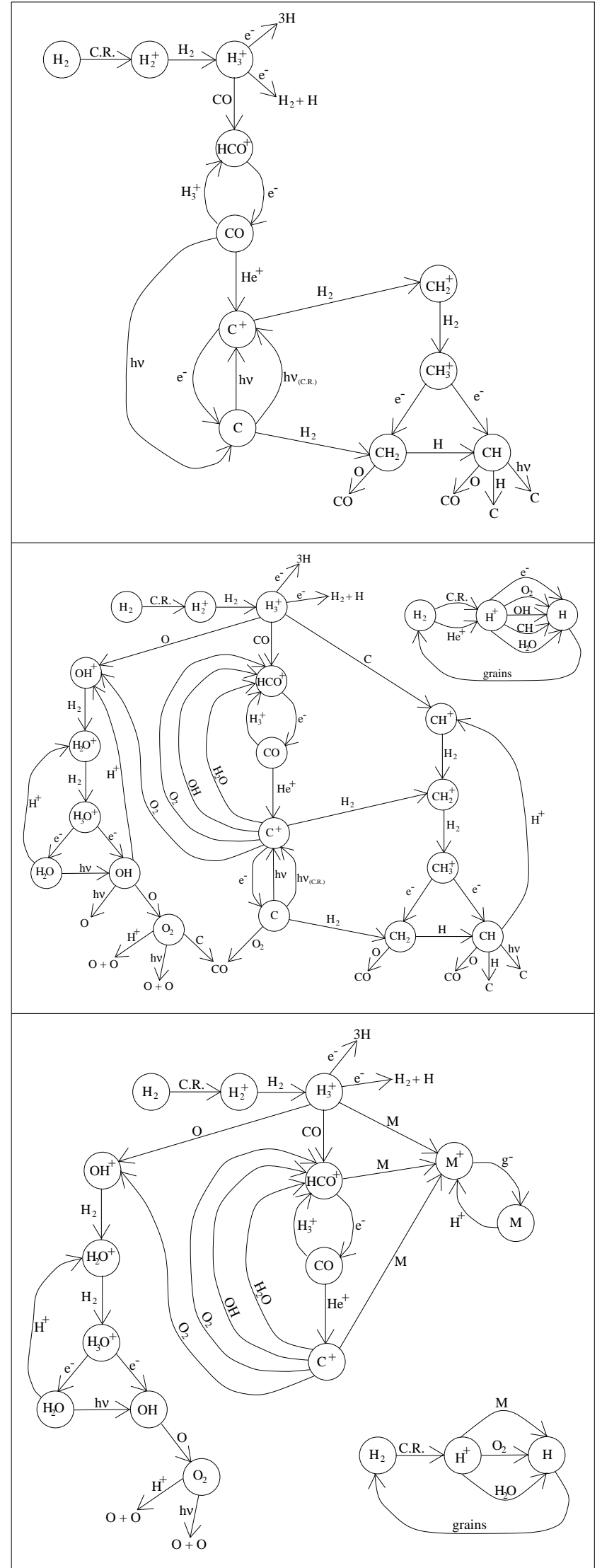

Fig. 2. Reduced networks for $n_{\mathrm{H}}=10^{3} \mathrm{~cm}^{-3}$ and low-metal abundance cases. Top: $A_{\mathrm{V}}=3$. Centre: $A_{\mathrm{V}}=3.5$. Bottom: $A_{\mathrm{V}}=5$. In each case, $\mathrm{He}^{+}$is produced in the reaction $\mathrm{He}+$ C.R. $\rightarrow \mathrm{He}^{+}+\mathrm{e}^{-}+$C.R. unit time per unit volume and removal rate per unit time per unit volume of species $j$ as $g_{j}$.

The first step in the reduction process is the specification of the species whose abundances are important. We shall suppose that there are $N$ such species. In addition to these species we shall assume that there are additional necessary species, i.e. those that are not of importance but whose abundances must be calculated in order to obtain accurate results for the important species.

The determination of the necessary species proceeds in a step-by-step process via the evaluation of

$B_{i}=\sum_{j=1}^{N^{\prime}}\left(\frac{n(i)}{g_{j}} \frac{\partial f_{j}}{\partial n(i)}\right)^{2}$

for all species (i.e. all choices of $i$ ). The summation is over $N^{\prime}$ species, all species already recognised to be important or necessary. $B_{i}$ is a measure of the sensitivity of the net formation rates of important and necessary species to the abundance of species $i$. If the difference between the smallest value of a $B_{i}$ obtained for one of the $N^{\prime}$ species and the largest value of a $B_{i}$ for any species not already deemed important or necessary is large, then the identification of necessary species is considered to be complete. Otherwise, the species previously not belonging to the set of identified important and necessary species and having the largest $B_{i}$ is added to that set and $B_{i}$ s are calculated for the new set of identified important and necessary species.

Once the final set of important and necessary species has been identified, a network consisting of all reactions of those species with one another but that do not produce species outside the final set is constructed. Subsequent analysis is restricted to this intermediate network. The rate coefficient of reaction $j$ is $k_{j}$. The quantities

$F_{i j}=\frac{k_{j}}{g_{i}} \frac{\partial f_{i}}{\partial k_{j}}$

are calculated. A matrix whose elements are the $F_{i j} \mathrm{~s}$ is defined. The eigenvalues and eigenvectors of the product of that matrix with its transpose are analysed. The details of the analysis are described by Tomlin et al. $(1992,1997)$.

Though more complicated methods can be used, the species in quasi-steady state were identified as those with $\left|\frac{f_{i}}{g_{i}}\right|<\frac{1}{3}$ in the reduced network.

\section{General approach to the application of the reduction method}

A wide range of densities and visual extinctions $\left(A_{\mathrm{V}} \mathrm{s}\right)$ obtain in Giant Molecular Cloud clumps and dense cores. We consider material in which the temperature $(T)$ is $20 \mathrm{~K}$.

Initially we restricted analysis to cases in which $n_{\mathrm{H}}$, the number density of hydrogen nuclei, is constant at $10^{3} \mathrm{~cm}^{-3}$. For this value of $n_{\mathrm{H}}$, we considered values of $A_{\mathrm{V}}$ of $1,3,3.5$, and 5 . For each of these $A_{\mathrm{V}}$ se ran both the full and large networks for cases in which elemental carbon was initially all in $\mathrm{CO}$; all other oxygen was assumed 


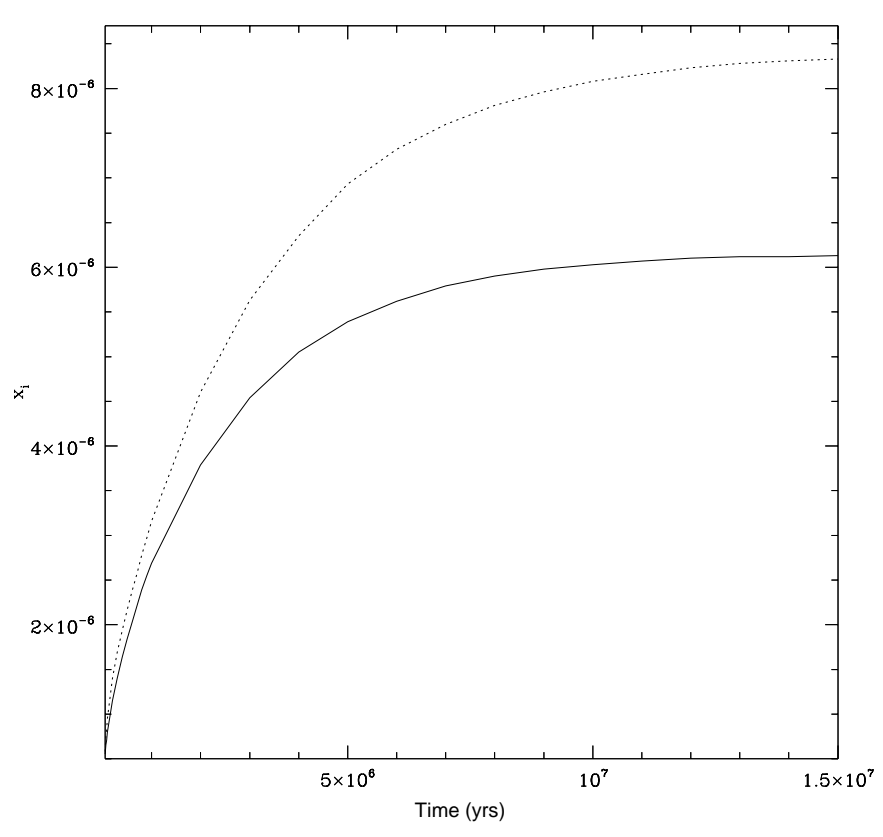

Fig. 3. Comparison of fractional ionisation results for $n_{\mathrm{H}}=$ $10^{3} \mathrm{~cm}^{-3}, A_{\mathrm{V}}=3$, and low-metal abundances. Full network: solid line. Reduced network: dotted line.

to be in atomic form and all other elements (except for hydrogen which was at the start taken to be completely in the form of $\mathrm{H}_{2}$ ) were assumed to be in neutral atoms and atomic ions initially. For $A_{\mathrm{V}}=5, n_{\mathrm{H}}=10^{3} \mathrm{~cm}^{-3}$ we also ran both the full and large networks with the initial conditions as described above except that carbon was assumed to be entirely in neutral atomic form. For all $A_{\mathrm{V}} \mathrm{s}$ at $n_{\mathrm{H}}=10^{3} \mathrm{~cm}^{-3}$ the equilibrium values of the fractional ionisation given by the full and large networks differed little.

For the $n_{\mathrm{H}}=10^{3} \mathrm{~cm}^{-3}$ cases described in the previous paragraph we used the large network as a starting point in our reduction analysis. The set of important and necessary species was found for each case through analysis at either the time when the CO abundance had fallen to twice its equilibrium value or the $\mathrm{C}^{+}$abundance had risen to half its equilibrium value. In each case once the species set was identified the intermediate network for it was used (with the same initial conditions as were used in the corresponding run with the large network) to generate time-dependent results for the chemical composition. This set of time-dependent results was then analysed at various times to reduce the size of the reaction network. Thus, a reduced network was obtained for each of several times for each of the five $n_{\mathrm{H}}=10^{3} \mathrm{~cm}^{-3}$ cases.

The full and large networks and the reduced networks were then used to perform runs for a large set of $n_{\mathrm{H}}$ (ranging from $500 \mathrm{~cm}^{-3}$ to $10^{5} \mathrm{~cm}^{-3}$ ) and $A_{\mathrm{V}}$ (ranging from 1 to 10$)$ grid points. For each grid point each of the two sets of chemical initial conditions was considered. We searched for regimes in $n_{\mathrm{H}}-A_{\mathrm{V}}$-initial condition space for which none of the five reduced networks obtained in the original $n_{\mathrm{H}}=10^{3} \mathrm{~cm}^{-3}$ analysis gave fractional ionisations at times greater than $10^{5}$ years that agreed to within $30 \%$ with the corresponding fractional ionisation given by the full network. The only regime in which none of the five original networks gave such agreement with the full network was for $n_{\mathrm{H}} \gtrsim 10^{4} \mathrm{~cm}^{-3}, A_{\mathrm{V}}=4$, and chemical initial conditions in which all carbon was initially in neutral atomic form. The entire reduction procedure was carried out for this regime leading to the production of a sixth reduced network.

The six reduced networks were put together to form a combined reduced network.

The procedure described in paragraph 2 of this section to the paragraph immediately above was carried out for low metal depletion which is defined in the next section. A very similar procedure was executed for high metal depletion, but a slightly different $n_{\mathrm{H}}, A_{\mathrm{V}}$ grid was adopted for it.

\section{The individual reduced networks}

We considered two sets of selective depletions which we refer to as the "low-metal" and "high-metal" depletion cases. Values of the elemental abundances with respect to hydrogen are listed for these two sets in Table 1.

We consider "low-metal" cases first in an effort to give some impression of how the network reduction was begun.

Table 2 gives the base ten logarithms of the values of the largest $B_{i}$ s obtained for the $n_{\mathrm{H}}=10^{3} \mathrm{~cm}^{-3}, A_{\mathrm{V}}=1$, low-metal case. $\mathrm{H}_{2}$ does not appear because its number density is specified, leading it to be excluded from the necessary species analysis. Figure 1 shows the reduced network, involving $\mathrm{H}_{2}$ and the thirteen species having the largest $B_{i} \mathrm{~s}$ in Table 2, identified with the normed rate analysis involving the matrix F. It involves 22 reactions.

The three panels of Fig. 2 show the networks obtained for the $n_{\mathrm{H}}=10^{3} \mathrm{~cm}^{-3}$, low-metal, $A_{\mathrm{V}}=3,3.5$ and 5 cases when all carbon is taken to be in CO initially. Including electrons, they involve 16, 24, and 20 species and 23,45 , and 28 reactions respectively. At $A_{\mathrm{V}}=3$ the removal of $\mathrm{CO}$ by $\mathrm{He}^{+}$must be included and at values of $A_{\mathrm{V}}$ greater than about 3 the inclusion of an extensive oxygen chemistry is necessary.

The only surface reactions that were found to be important are those involving the neutralisation of charged species. This statement is true for all reduced networks.

Figure 3 shows a comparison of the results for the time evolution of the fractional ionisation, $x_{\mathrm{i}}=\frac{n\left(\mathrm{e}^{-}\right)}{n_{\mathrm{H}}}$, given by the appropriate individual reduced network and the full network for the $n_{\mathrm{H}}=10^{3} \mathrm{~cm}^{-3}$, low-metal, $A_{\mathrm{V}}=3$ case when all carbon is initially in CO.

\section{The combined reduced networks}

Two combined reduced networks were produced from the smaller reduced networks like those depicted in Figs. 1 and 2. One combined reduced network is appropriate for low-metal abundances and incorporates all reactions indicated in those figures. Table 3 is a list of the reactions 
Table 3. Combined reduced reaction set - low metal abundances.

\begin{tabular}{|c|c|c|c|}
\hline 1 & $\mathrm{H}+\mathrm{CH} \rightarrow \mathrm{C}+\mathrm{H}_{2}$ & 37 & $\mathrm{CH}_{5}^{+}+\mathrm{O} \rightarrow \mathrm{H}_{3} \mathrm{O}^{+}+\mathrm{CH}_{2}$ \\
\hline 2 & $\mathrm{H}+\mathrm{CH}_{2} \rightarrow \mathrm{CH}+\mathrm{H}_{2}$ & 38 & $\mathrm{CH}_{5}^{+}+\mathrm{CO} \rightarrow \mathrm{HCO}^{+}+\mathrm{CH}_{4}$ \\
\hline 3 & $\mathrm{H}_{2}+\mathrm{C} \rightarrow \mathrm{CH}_{2}+\mathrm{h} \nu$ & 39 & $\mathrm{H}_{2} \mathrm{O}^{+}+\mathrm{H}_{2} \rightarrow \mathrm{H}_{3} \mathrm{O}^{+}+\mathrm{H}$ \\
\hline 4 & $\mathrm{C}+\mathrm{OH} \rightarrow \mathrm{CO}+\mathrm{H}$ & 40 & $\mathrm{H}_{3} \mathrm{O}^{+}+\mathrm{Na} \rightarrow \mathrm{Na}^{+}+\mathrm{H}_{2} \mathrm{O}+\mathrm{H}$ \\
\hline 5 & $\mathrm{C}+\mathrm{O}_{2} \rightarrow \mathrm{CO}+\mathrm{O}$ & 41 & $\mathrm{HCO}^{+}+\mathrm{C} \rightarrow \mathrm{CH}^{+}+\mathrm{CO}$ \\
\hline 6 & $\mathrm{O}+\mathrm{CH} \rightarrow \mathrm{CO}+\mathrm{H}$ & 42 & $\mathrm{HCO}^{+}+\mathrm{Na} \rightarrow \mathrm{Na}^{+}+\mathrm{CO}+\mathrm{H}$ \\
\hline 7 & $\mathrm{O}+\mathrm{CH} \rightarrow \mathrm{HCO}^{+}+\mathrm{e}^{-}$ & 43 & $\mathrm{H}^{+}+\mathrm{e}^{-} \rightarrow \mathrm{H}+\mathrm{h} \nu$ \\
\hline 8 & $\mathrm{O}+\mathrm{CH}_{2} \rightarrow \mathrm{CO}+\mathrm{H}+\mathrm{H}$ & 44 & $\mathrm{H}_{3}^{+}+\mathrm{e}^{-} \rightarrow \mathrm{H}_{2}+\mathrm{H}$ \\
\hline 9 & $\mathrm{O}+\mathrm{OH} \rightarrow \mathrm{O}_{2}+\mathrm{H}$ & 45 & $\mathrm{H}_{3}^{+}+\mathrm{e}^{-} \rightarrow \mathrm{H}+\mathrm{H}+\mathrm{H}$ \\
\hline 10 & $\mathrm{H}^{+}+\mathrm{Na} \rightarrow \mathrm{Na}^{+}+\mathrm{H}$ & 46 & $\mathrm{C}^{+}+\mathrm{e}^{-} \rightarrow \mathrm{C}+\mathrm{h} \nu$ \\
\hline 11 & $\mathrm{H}^{+}+\mathrm{CH} \rightarrow \mathrm{CH}^{+}+\mathrm{H}$ & 47 & $\mathrm{CH}_{3}^{+}+\mathrm{e}^{-} \rightarrow \mathrm{CH}_{2}+\mathrm{H}$ \\
\hline 12 & $\mathrm{H}^{+}+\mathrm{OH} \rightarrow \mathrm{OH}^{+}+\mathrm{H}$ & 48 & $\mathrm{CH}_{3}^{+}+\mathrm{e}^{-} \rightarrow \mathrm{CH}+\mathrm{H}_{2}$ \\
\hline 13 & $\mathrm{H}^{+}+\mathrm{H}_{2} \mathrm{O} \rightarrow \mathrm{H}_{2} \mathrm{O}^{+}+\mathrm{H}$ & 49 & $\mathrm{CH}_{3}^{+}+\mathrm{e}^{-} \rightarrow \mathrm{CH}+\mathrm{H}+\mathrm{H}$ \\
\hline 14 & $\mathrm{H}^{+}+\mathrm{O}_{2} \rightarrow \mathrm{O}+\mathrm{O}+\mathrm{H}$ & 50 & $\mathrm{CH}_{5}^{+}+\mathrm{e}^{-} \rightarrow \mathrm{CH}_{4}+\mathrm{H}$ \\
\hline 15 & $\mathrm{H}_{2}^{+}+\mathrm{H}_{2} \rightarrow \mathrm{H}_{3}^{+}+\mathrm{H}$ & 51 & $\mathrm{H}_{3} \mathrm{O}^{+}+\mathrm{e}^{-} \rightarrow \mathrm{H}_{2} \mathrm{O}+\mathrm{H}$ \\
\hline 16 & $\mathrm{H}_{3}^{+}+\mathrm{Na} \rightarrow \mathrm{Na}^{+}+\mathrm{H}+\mathrm{H}_{2}$ & 52 & $\mathrm{H}_{3} \mathrm{O}^{+}+\mathrm{e}^{-} \rightarrow \mathrm{OH}+\mathrm{H}+\mathrm{H}$ \\
\hline 17 & $\mathrm{H}_{3}^{+}+\mathrm{H}_{2} \mathrm{O} \rightarrow \mathrm{H}_{3} \mathrm{O}^{+}+\mathrm{H}_{2}$ & 53 & $\mathrm{HCO}^{+}+\mathrm{e}^{-} \rightarrow \mathrm{CO}+\mathrm{H}$ \\
\hline 18 & $\mathrm{H}_{3}^{+}+\mathrm{C} \rightarrow \mathrm{CH}^{+}+\mathrm{H}_{2}$ & 54 & $\mathrm{Na}^{+}+\mathrm{e}^{-} \rightarrow \mathrm{Na}+\mathrm{h} \nu$ \\
\hline 19 & $\mathrm{H}_{3}^{+}+\mathrm{O} \rightarrow \mathrm{OH}^{+}+\mathrm{H}_{2}$ & 55 & $\mathrm{He}+$ C.R. $\rightarrow \mathrm{He}^{+}+\mathrm{e}^{-}+$C.R. \\
\hline 20 & $\mathrm{H}_{3}^{+}+\mathrm{CO} \rightarrow \mathrm{HCO}^{+}+\mathrm{H}_{2}$ & 56 & $\mathrm{H}_{2}+$ C.R. $\rightarrow \mathrm{H}^{+}+\mathrm{e}^{-}+\mathrm{H}+$ C.R. \\
\hline 21 & $\mathrm{He}^{+}+\mathrm{H}_{2} \rightarrow \mathrm{H}_{2}^{+}+\mathrm{He}$ & 57 & $\mathrm{H}_{2}+$ C.R. $\rightarrow \mathrm{H}_{2}^{+}+\mathrm{e}^{-}+$C.R. \\
\hline 22 & $\mathrm{He}^{+}+\mathrm{CO} \rightarrow \mathrm{C}^{+}+\mathrm{O}+\mathrm{He}$ & 58 & $\mathrm{C}+\mathrm{h} \nu \rightarrow \mathrm{C}^{+}+\mathrm{e}^{-}$ \\
\hline 23 & $\mathrm{C}^{+}+\mathrm{Na} \rightarrow \mathrm{Na}^{+}+\mathrm{C}$ & 59 & $\mathrm{CH}+\mathrm{h} \nu \rightarrow \mathrm{CH}^{+}+\mathrm{e}^{-}$ \\
\hline 24 & $\mathrm{C}^{+}+\mathrm{H}_{2} \rightarrow \mathrm{CH}_{2}^{+}+\mathrm{h} \nu$ & 60 & $\mathrm{CH}+\mathrm{h} \nu \rightarrow \mathrm{C}+\mathrm{H}$ \\
\hline 25 & $\mathrm{C}^{+}+\mathrm{CH} \rightarrow \mathrm{CH}^{+}+\mathrm{C}$ & 61 & $\mathrm{CH}_{2}+\mathrm{h} \nu \rightarrow \mathrm{CH}_{2}^{+}+\mathrm{e}^{-}$ \\
\hline 26 & $\mathrm{C}^{+}+\mathrm{OH} \rightarrow \mathrm{HCO}^{+}+\mathrm{H}+\mathrm{H}$ & 62 & $\mathrm{CH}_{2}+\mathrm{h} \nu \rightarrow \mathrm{CH}+\mathrm{H}$ \\
\hline 27 & $\mathrm{C}^{+}+\mathrm{H}_{2} \mathrm{O} \rightarrow \mathrm{HCO}^{+}+\mathrm{H}$ & 63 & $\mathrm{OH}+\mathrm{h} \nu \rightarrow \mathrm{O}+\mathrm{H}$ \\
\hline 28 & $\mathrm{C}^{+}+\mathrm{O}_{2} \rightarrow \mathrm{HCO}^{+}+\mathrm{O}+\mathrm{H}$ & 64 & $\mathrm{CH}_{4}+\mathrm{h} \nu \rightarrow \mathrm{CH}_{2}+\mathrm{H}_{2}$ \\
\hline 29 & $\mathrm{C}^{+}+\mathrm{O}_{2} \rightarrow \mathrm{OH}^{+}+\mathrm{CO}+\mathrm{H}$ & 65 & $\mathrm{H}_{2} \mathrm{O}+\mathrm{h} \nu \rightarrow \mathrm{OH}+\mathrm{H}$ \\
\hline 30 & $\mathrm{C}^{+}+\mathrm{CH}_{4} \rightarrow \mathrm{CO}+\mathrm{CH}+\mathrm{H}+\mathrm{H}+\mathrm{H}$ & 66 & $\mathrm{O}_{2}+\mathrm{h} \nu \rightarrow \mathrm{O}+\mathrm{O}$ \\
\hline 31 & $\mathrm{CH}^{+}+\mathrm{H}_{2} \rightarrow \mathrm{CH}_{2}^{+}+\mathrm{H}$ & 67 & $\mathrm{CO}+\mathrm{h} \nu \rightarrow \mathrm{C}+\mathrm{O}$ \\
\hline 32 & $\mathrm{CH}_{2}^{+}+\mathrm{H}_{2} \rightarrow \mathrm{CH}_{3}^{+}+\mathrm{H}$ & 68 & $\mathrm{C}+\mathrm{h} \nu_{\text {C.R. }} \rightarrow \mathrm{C}^{+}+\mathrm{e}^{-}$ \\
\hline 33 & $\mathrm{CH}_{3}^{+}+\mathrm{O} \rightarrow \mathrm{HCO}^{+}+\mathrm{H}_{2}$ & 69 & $\mathrm{CH}_{4}+\mathrm{h} \nu_{\text {C.R. }} \rightarrow \mathrm{CH}_{2}+\mathrm{H}_{2}$ \\
\hline 34 & $\mathrm{CH}_{3}^{+}+\mathrm{H}_{2} \rightarrow \mathrm{CH}_{5}^{+}+\mathrm{h} \nu$ & 70 & $\mathrm{CO}+\mathrm{h} \nu_{\text {C.R. }} \rightarrow \mathrm{C}+\mathrm{O}$ \\
\hline 35 & $\mathrm{OH}^{+}+\mathrm{H}_{2} \rightarrow \mathrm{H}_{2} \mathrm{O}^{+}+\mathrm{H}$ & 71 & $\mathrm{Na}^{+}+\mathrm{g}^{-} \rightarrow \mathrm{Na}+\mathrm{g}^{0}$ \\
\hline 36 & $\mathrm{CH}_{5}^{+}+\mathrm{C} \rightarrow \mathrm{CH}^{+}+\mathrm{CH}_{4}$ & & \\
\hline
\end{tabular}

in the combined reduced network for the low-metal abundances. $\mathrm{h} \nu_{\text {(C.R.) }}$ indicates that a photon emitted in the cloud or clump as a consequence of cosmic ray induced ionisation is included in the reaction. Including electrons, 28 species take part in these reactions. Table 4 is an analogous list of reactions in the combined reduced network for the high-metal abundances; 29 species are included in these reactions.

We have simplified the sulphur chemistry in the combined reduced network for high-metal abundances.
This allowed us to keep the species list somewhat smaller without loss of accuracy in the fractional ionisation calculations. The simplifications were:

1. The rate at which reactions of $\mathrm{S}$ with $\mathrm{OH}$ produce SO was set to the sum of rates of the reactions $\mathrm{S}+\mathrm{OH} \rightarrow \mathrm{SO}+\mathrm{H}$ and $\mathrm{S}+\mathrm{OH} \rightarrow \mathrm{HS}+\mathrm{O}$ HS was excluded from the network;

2. The radiative association reaction of $\mathrm{S}^{+}$with $\mathrm{H}_{2}$ was assumed to result immediately in the production of $\mathrm{SO}$, so that $\mathrm{H}_{2} \mathrm{~S}^{+}$could be excluded; 
Table 4. Combined reduced reaction set - high metal abundances.

\begin{tabular}{|c|c|c|c|}
\hline 1 & $\mathrm{H}+\mathrm{CH} \rightarrow \mathrm{C}+\mathrm{H}_{2}$ & 34 & $\mathrm{~S}^{+}+\mathrm{Na} \rightarrow \mathrm{Na}^{+}+\mathrm{S}$ \\
\hline 2 & $\mathrm{H}+\mathrm{CH}_{2} \rightarrow \mathrm{CH}+\mathrm{H}_{2}$ & 35 & $\mathrm{H}_{3}^{+}+\mathrm{e}^{-} \rightarrow \mathrm{H}_{2}+\mathrm{H}$ \\
\hline 3 & $\mathrm{O}+\mathrm{CH} \rightarrow \mathrm{CO}+\mathrm{H}$ & 36 & $\mathrm{H}_{3}^{+}+\mathrm{e}^{-} \rightarrow \mathrm{H}+\mathrm{H}+\mathrm{H}$ \\
\hline 4 & $\mathrm{O}+\mathrm{CH}_{2} \rightarrow \mathrm{CO}+\mathrm{H}+\mathrm{H}$ & 37 & $\mathrm{H}_{3} \mathrm{O}^{+}+\mathrm{e}^{-} \rightarrow \mathrm{H}_{2} \mathrm{O}+\mathrm{H}$ \\
\hline 5 & $\mathrm{C}+\mathrm{O}_{2} \rightarrow \mathrm{CO}+\mathrm{O}$ & 38 & $\mathrm{H}_{3} \mathrm{O}^{+}+\mathrm{e}^{-} \rightarrow \mathrm{OH}+\mathrm{H}+\mathrm{H}$ \\
\hline 6 & $\mathrm{C}+\mathrm{SO} \rightarrow \mathrm{CO}+\mathrm{S}$ & 39 & $\mathrm{C}^{+}+\mathrm{e}^{-} \rightarrow \mathrm{C}+\mathrm{h} \nu$ \\
\hline 7 & $\mathrm{C}+\mathrm{SO} \rightarrow \mathrm{CS}+\mathrm{O}$ & 40 & $\mathrm{CH}_{3}^{+}+\mathrm{e}^{-} \rightarrow \mathrm{CH}_{2}+\mathrm{H}$ \\
\hline 8 & $\mathrm{H} 2+\mathrm{C} \rightarrow \mathrm{CH} 2+\mathrm{h} \nu$ & 41 & $\mathrm{CH}_{3}^{+}+\mathrm{e}^{-} \rightarrow \mathrm{CH}+\mathrm{H}_{2}$ \\
\hline 9 & $\mathrm{O}+\mathrm{OH} \rightarrow \mathrm{O}_{2}+\mathrm{H}$ & 42 & $\mathrm{CH}_{3}^{+}+\mathrm{e}^{-} \rightarrow \mathrm{CH}+\mathrm{H}+\mathrm{H}$ \\
\hline 10 & $\mathrm{~S}+\mathrm{OH} \rightarrow \mathrm{SO}+\mathrm{H}$ & 43 & $\mathrm{HCO}^{+}+\mathrm{e}^{-} \rightarrow \mathrm{CO}+\mathrm{H}$ \\
\hline 11 & $\mathrm{~S}+\mathrm{O}_{2} \rightarrow \mathrm{SO}+\mathrm{O}$ & 44 & $\mathrm{~S}^{+}+\mathrm{e}^{-} \rightarrow \mathrm{S}+\mathrm{h} \nu$ \\
\hline 12 & $\mathrm{H}_{2}^{+}+\mathrm{H}_{2} \rightarrow \mathrm{H}_{3}^{+}+\mathrm{H}$ & 45 & $\mathrm{Na}^{+}+\mathrm{e}^{-} \rightarrow \mathrm{Na}+\mathrm{h} \nu$ \\
\hline 13 & $\mathrm{H}_{3}^{+}+\mathrm{C} \rightarrow \mathrm{CH}^{+}+\mathrm{H}_{2}$ & 46 & $\mathrm{H}_{2}+$ C.R. $\rightarrow \mathrm{H}_{2}^{+}+\mathrm{e}^{-}+$C.R. \\
\hline 14 & $\mathrm{H}_{3}^{+}+\mathrm{O} \rightarrow \mathrm{OH}^{+}+\mathrm{H}_{2}$ & 47 & $\mathrm{He}+$ C.R. $\rightarrow \mathrm{He}^{+}+\mathrm{e}^{-}+$C.R. \\
\hline 15 & $\mathrm{H}_{3}^{+}+\mathrm{CO} \rightarrow \mathrm{HCO}^{+}+\mathrm{H}_{2}$ & 48 & $\mathrm{H}_{2} \mathrm{O}+\mathrm{h} \nu \rightarrow \mathrm{OH}+\mathrm{H}$ \\
\hline 16 & $\mathrm{H}_{3}^{+}+\mathrm{Na} \rightarrow \mathrm{Na}^{+}+\mathrm{H}+\mathrm{H}_{2}$ & 49 & $\mathrm{O}_{2}+\mathrm{h} \nu \rightarrow \mathrm{O}+\mathrm{O}$ \\
\hline 17 & $\mathrm{H}_{3}^{+}+\mathrm{H}_{2} \mathrm{O} \rightarrow \mathrm{H}_{3} \mathrm{O}^{+}+\mathrm{H}_{2}$ & 50 & $\mathrm{C}+\mathrm{h} \nu \rightarrow \mathrm{C}^{+}+\mathrm{e}^{-}$ \\
\hline 18 & $\mathrm{He}^{+}+\mathrm{H}_{2} \rightarrow \mathrm{H}_{2}^{+}+\mathrm{He}$ & 51 & $\mathrm{CH}+\mathrm{h} \nu \rightarrow \mathrm{CH}^{+}+\mathrm{e}^{-}$ \\
\hline 19 & $\mathrm{He}^{+}+\mathrm{CO} \rightarrow \mathrm{C}^{+}+\mathrm{O}+\mathrm{He}$ & 52 & $\mathrm{CH}+\mathrm{h} \nu \rightarrow \mathrm{C}+\mathrm{H}$ \\
\hline 20 & $\mathrm{He}^{+}+\mathrm{CS} \rightarrow \mathrm{S}^{+}+\mathrm{C}+\mathrm{He}$ & 53 & $\mathrm{CH}_{2}+\mathrm{h} \nu \rightarrow \mathrm{CH}_{2}^{+}+\mathrm{e}^{-}$ \\
\hline 21 & $\mathrm{He}^{+}+\mathrm{CS} \rightarrow \mathrm{C}^{+}+\mathrm{S}+\mathrm{He}$ & 54 & $\mathrm{CH}_{2}+\mathrm{h} \nu \rightarrow \mathrm{CH}+\mathrm{H}$ \\
\hline 22 & $\mathrm{C}^{+}+\mathrm{H}_{2} \rightarrow \mathrm{CH}_{2}^{+}+\mathrm{h} \nu$ & 55 & $\mathrm{CO}+\mathrm{h} \nu \rightarrow \mathrm{C}+\mathrm{O}$ \\
\hline 23 & $\mathrm{C}^{+}+\mathrm{CH} \rightarrow \mathrm{CH}^{+}+\mathrm{C}$ & 56 & $\mathrm{~S}+\mathrm{h} \nu \rightarrow \mathrm{S}^{+}+\mathrm{e}^{-}$ \\
\hline 24 & $\mathrm{C}^{+}+\mathrm{H}_{2} \mathrm{O} \rightarrow \mathrm{HCO}^{+}+\mathrm{H}$ & 57 & $\mathrm{CS}+\mathrm{h} \nu \rightarrow \mathrm{C}+\mathrm{S}$ \\
\hline 25 & $\mathrm{C}^{+}+\mathrm{O}_{2} \rightarrow \mathrm{HCO}^{+}+\mathrm{O}+\mathrm{H}$ & 58 & $\mathrm{C}+\mathrm{h} \nu_{\text {C.R. }} \rightarrow \mathrm{C}^{+}+\mathrm{e}^{-}$ \\
\hline 26 & $\mathrm{C}^{+}+\mathrm{O}_{2} \rightarrow \mathrm{OH}^{+}+\mathrm{CO}+\mathrm{H}$ & 59 & $\mathrm{H}_{2} \mathrm{O}+\mathrm{h} \nu_{\text {C.R. }} \rightarrow \mathrm{OH}+\mathrm{H}$ \\
\hline 27 & $\mathrm{C}^{+}+\mathrm{S} \rightarrow \mathrm{S}^{+}+\mathrm{C}$ & 60 & $\mathrm{O}_{2}+\mathrm{h} \nu_{\text {C.R. }} \rightarrow \mathrm{O}+\mathrm{O}$ \\
\hline 28 & $\mathrm{C}^{+}+\mathrm{Na} \rightarrow \mathrm{Na}^{+}+\mathrm{C}$ & 61 & $\mathrm{CO}+\mathrm{h} \nu_{\text {C.R. }} \rightarrow \mathrm{C}+\mathrm{O}$ \\
\hline 29 & $\mathrm{CH}^{+}+\mathrm{H}_{2} \rightarrow \mathrm{CH}_{2}^{+}+\mathrm{H}$ & 62 & $\mathrm{~S}+\mathrm{h} \nu_{\text {C.R. }} \rightarrow \mathrm{S}^{+}+\mathrm{e}^{-}$ \\
\hline 30 & $\mathrm{CH}_{2}^{+}+\mathrm{H}_{2} \rightarrow \mathrm{CH}_{3}^{+}+\mathrm{H}$ & 63 & $\mathrm{CS}+\mathrm{h} \nu_{\text {C.R. }} \rightarrow \mathrm{C}+\mathrm{S}$ \\
\hline 31 & $\mathrm{OH}^{+}+\mathrm{H}_{2} \rightarrow \mathrm{H}_{2} \mathrm{O}^{+}+\mathrm{H}$ & 64 & $\mathrm{~S}^{+}+\mathrm{g}^{-} \rightarrow \mathrm{S}+\mathrm{g}^{0}$ \\
\hline 32 & $\mathrm{H}_{2} \mathrm{O}^{+}+\mathrm{H}_{2} \rightarrow \mathrm{H}_{3} \mathrm{O}^{+}+\mathrm{H}$ & 65 & $\mathrm{Na}^{+}+\mathrm{g}^{-} \rightarrow \mathrm{Na}+\mathrm{g}^{0}$ \\
\hline 33 & $\mathrm{HCO}^{+}+\mathrm{Na} \rightarrow \mathrm{Na}^{+}+\mathrm{CO}+\mathrm{H}$ & & \\
\hline
\end{tabular}

3. The reactions of $\mathrm{S}^{+}$with $\mathrm{OH}$ and $\mathrm{O}_{2}$ were assumed to generate $\mathrm{S}$ and $\mathrm{O}$ immediately so that $\mathrm{SO}^{+}$could be excluded from the network;

4. All reactions removing $\mathrm{SO}$ except

$$
\begin{aligned}
& \mathrm{C}+\mathrm{SO} \rightarrow \mathrm{CS}+\mathrm{O} \\
& \mathrm{C}+\mathrm{SO} \rightarrow \mathrm{CO}+\mathrm{S}
\end{aligned}
$$

were excluded.

Simplifications 1 to 3 are justified because rapid sequences convert $\mathrm{SO}^{+}$and $\mathrm{H}_{2} \mathrm{~S}^{+}$to $\mathrm{S}$ and $\mathrm{SO}$ respectively once those ions are formed. Simplification 4 is valid in part because of the dominance of those removal mechanisms and because the products of some other reactions removing $\mathrm{SO}$ enter sequences that re-form SO quickly.

\section{Collapse and quasi-steady state species}

The fractional ionisation is of particular relevance to collapse that is regulated by ambipolar diffusion. In this section, we test the reliability of various networks for the calculation of the fractional ionisation in two different collapse scenarios. In some runs, some of the species are assumed to be always nearly in steady state. In both collapse scenarios $n_{\mathrm{H}}=10^{3} \mathrm{~cm}^{-3}, A_{\mathrm{V}}=3.0$, and chemical equilibrium obtains, initially.

In one scenario

$\frac{\mathrm{d} n_{\mathrm{H}}}{\mathrm{d} t}=B \frac{n_{\mathrm{H}}}{t_{\mathrm{ff}}}$ 

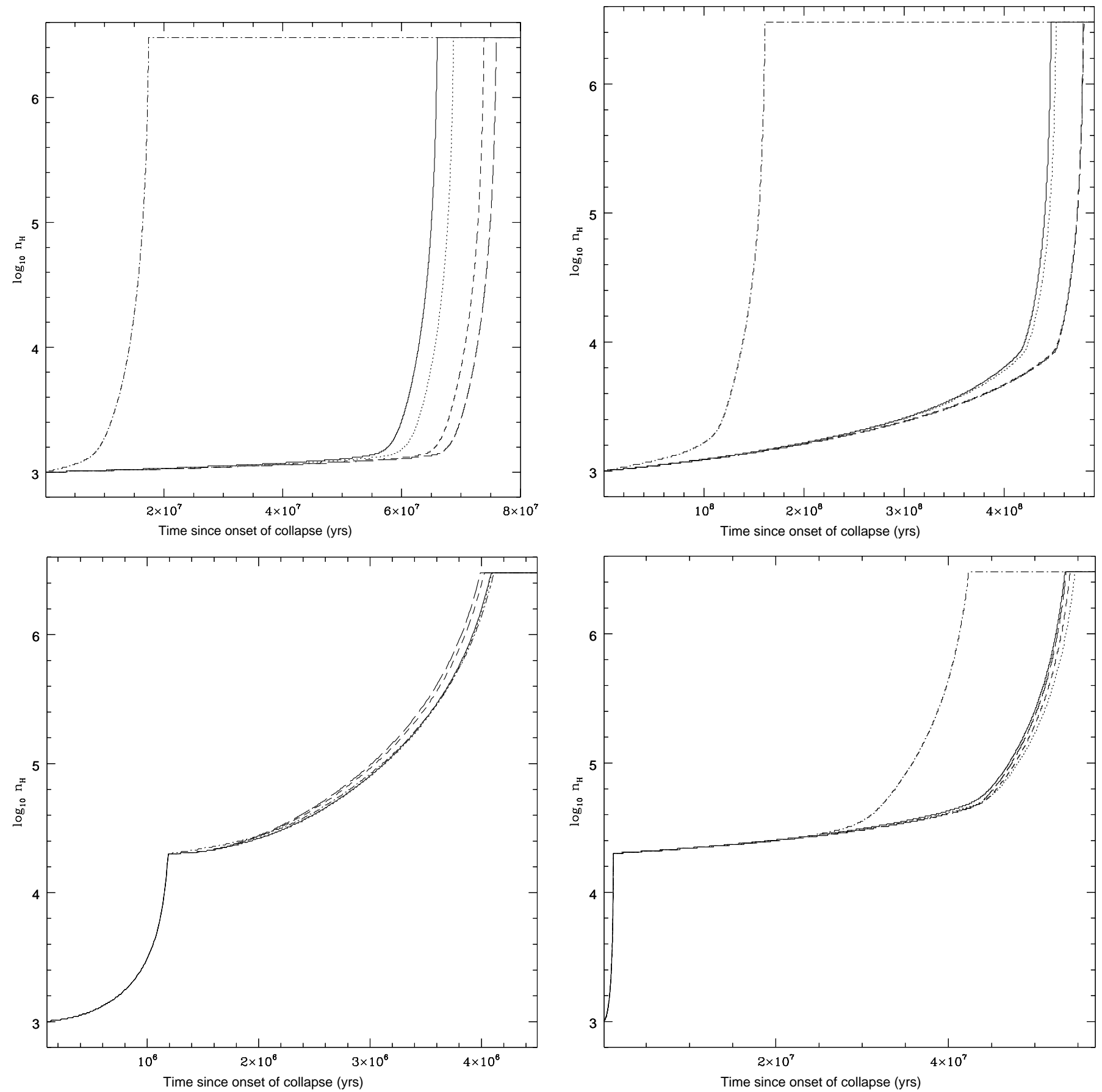

Fig. 4. Number density as a function of time in collapse models. Full network: solid line. Large network: dotted line. Combined reduced network: short-dashed line. QSS treatment of combined reduced network: long-dashed line. Ciolek \& Mouschovias (1995) network: dot-dashed line. Top left: low-metal, ambipolar diffusion regulated. Top right: high-metal, ambipolar diffusion regulated. Bottom left: low-metal, two-phase. Bottom right: high-metal, two-phase.

where

$$
\begin{aligned}
& t_{\mathrm{ff}}=\left(\frac{3 \pi}{32 G n_{\mathrm{H}} m_{\mathrm{H}}}\right)^{\frac{1}{2}} \\
& B^{-1}=2.2\left(\frac{n\left(\mathrm{e}^{-}\right)}{10^{-3} \mathrm{~cm}^{-3}}\right)\left(\frac{n_{\mathrm{H}}}{10^{5} \mathrm{~cm}^{-3}}\right)^{-\frac{1}{2}}
\end{aligned}
$$

and $m_{\mathrm{H}}$ is the mass of the hydrogen atom. The choice for the form of $B$ is based on a result given by
Mouschovias (1987). In this scenario which we will refer to as the "ambipolar diffusion regulated" scenario $A_{\mathrm{V}}=3.0\left(\frac{n_{\mathrm{H}}}{10^{3} \mathrm{~cm}^{-3}}\right)^{\frac{2}{3}}$. Collapse was assumed to cease at
$n_{\mathrm{H}}=3 \times 10^{6} \mathrm{~cm}^{-3}$.

In the other scenario, collapse is initially as in planeparallel gravitational free fall at a constant value of $A_{\mathrm{V}}$. This initial collapse phase is somewhat similar to what may occur if support by hydromagnetic waves of a clump 

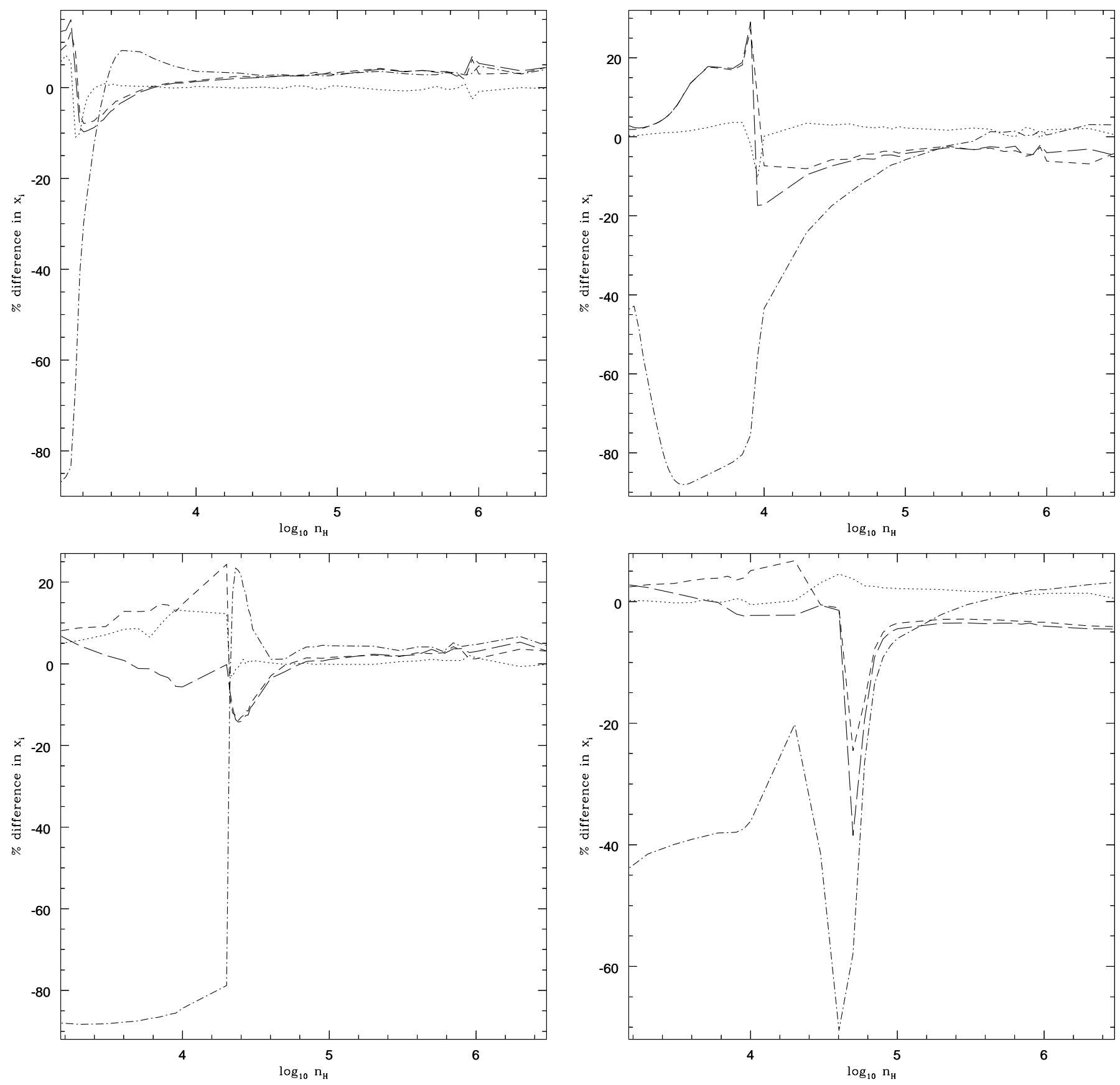

Fig. 5. Percentage discrepancy between fractional ionisation given by different networks as a function of number density in collapse models. Percentage discrepancy between network $k$ and network $l$ is defined as $\frac{100\left(x_{\mathrm{i}, k}-x_{\mathrm{i}, l}\right)}{x_{\mathrm{i}, k}}$. Discrepancy between full network and large network: dotted line. Discrepancy between large network and combined reduced network: short-dashed line. Discrepancy between large network and QSS treatment of combined network: long-dashed line. Discrepancy between large network and Ciolek \& Mouschovias (1995) network: dot-dashed line. Top left: low-metal, ambipolar diffusion regulated. Top right: high-metal, ambipolar diffusion regulated. Bottom left: low-metal, two-phase. Bottom right: high-metal, two-phase.

with magnetic pressure far in excess of its thermal pressure were to be reduced suddenly (cf. Ruffle et al. 1998). The second phase of collapse begins when $n_{\mathrm{H}}$ reaches $2 \times 10^{4} \mathrm{~cm}^{-3}$; subsequently collapse is governed by Eqs. (5) to (7) and $A_{\mathrm{V}}=3.0\left(\frac{n_{\mathrm{H}}}{2 \times 10^{4} \mathrm{~cm}^{-3}}\right)^{\frac{2}{3}}$. We will refer to this as the "two-phase" collapse scenario; it is similar to a collapse picture considered by Ruffle et al. (1998).
Results given by the combined reduced networks for each of the depletion sets were used to identify QuasiSteady State (QSS) species. If $\left|\frac{f_{i}}{g_{i}}\right|<\frac{1}{3}$ for species $i$ at a particular time, that species is considered to be QSS at that time. QSS species were identified at times of $10^{5}$, $6 \times 10^{5}, 10^{6}, 1.2 \times 10^{6}, 1.5 \times 10^{6}, 2 \times 10^{6}, 2.2 \times 10^{6}$, and $10^{7}$ years in the two-phase collapse scenario. All species, 
except for $\mathrm{H}, \mathrm{H}_{2}, \mathrm{C}, \mathrm{O}, \mathrm{CO}, \mathrm{CH}_{4}$, and $\mathrm{O}_{2}$, were found to be in QSS at all of those times for both sets of depletions. In models designated as QSS models the abundances of only those species listed immediately above were calculated by the integration of differential equations; the abundances of other species were obtained algebraically in through the assumption that the corresponding $f_{i}$ s are all identically zero.

For both collapse scenarios and for both sets of depletions we calculated the time evolution of $n_{\mathrm{H}}$ and $x_{\mathrm{i}}$ with the full, large, and combined reduced networks. We also used QSS models based on the combined reduced networks and, in addition, a network proposed by Ciolek \& Mouschovias (1995). When employing their network we assumed $\frac{n(\mathrm{OH})}{n_{\mathrm{H}}}=2.47 \times 10^{-10}$ and $\frac{n\left(\mathrm{H}_{2} \mathrm{O}\right)}{n_{\mathrm{H}}}=1.98 \times 10^{-7}$ (values given by the full network at the end of the collapse) because to use the Ciolek \& Mouschovias network these quantities must be specified; we modified their network by neglecting $\mathrm{Mg}, \mathrm{Mg}^{+}, \mathrm{Fe}, \mathrm{Fe}^{+}, \mathrm{Si}$, and $\mathrm{Si}^{+}$because at low temperatures these species behave very much like $\mathrm{Na}$ and $\mathrm{Na}^{+}$, which we did include.

Figure 4 shows results for $n_{\mathrm{H}}$ as a function of time for each of the various models. The combined reduced networks are seen to be sufficient for the calculation of accurate collapse histories. Figure 5 shows results for the discrepancy between values of $x_{1}$ for each of a number of pairs of models.

In the collapse models the Ciolek \& Mouschovias (1995) network gives good values for $x_{\mathrm{i}}$ as a function of $n_{\mathrm{H}}$ in dark regions (where $A_{\mathrm{V}} \gtrsim 5$ ) for a wide range of values for $n_{\mathrm{H}}$. It also gives reliable values of $x_{\mathrm{i}}$ as a function of $n_{\mathrm{H}}$ at lower values of $A_{\mathrm{V}}\left(A_{\mathrm{V}} \gtrsim 3\right)$ for values of $n_{\mathrm{H}}$ in excess of about $2 \times 10^{4} \mathrm{~cm}^{-3}$. The large network gives accurate values of $x_{\mathrm{i}}$ for all ranges of $n_{\mathrm{H}}$ and $A_{\mathrm{V}}$ in the collapse models, as does the combined reduced network, whether it is treated by the integration of differential equations or with the QSS approach described above. As seen from Figs. 4 and 5, even modest discrepancies in the results for $x_{\mathrm{i}}$ as a function of $n_{\mathrm{H}}$ have corresponding discrepancies between $n_{\mathrm{H}}$ versus $t$ curves that are more significant.

\section{Conclusions}

We have identified a combined reduced network for each of two sets of depletions that gives values of the fractional ionisation that over a wide range of conditions are in good agreement with those obtained with the full network.

The importance of the identification of such networks is illustrated simply by a comparison of CPU time required to complete calculations like those for which results are given in the top left panel of Fig. 4. On a Sun Ultra 1 Workstation the calculation with the full network required about an hour and that with the combined network took less than a minute.

Acknowledgements. JGLR was supported by a PPARC studentship. DPR was supported by a grant from the Leverhulme Trust.

\section{References}

Bertoldi, F., \& McKee, C. F. 1992, ApJ, 395, 140

Ciolek, G. E., \& Mouschovias, T. Ch. 1995, ApJ, 454, 194

Coker, R. F., Rae, J. G. L., \& Hartquist, T. W., 2000, A\&A, 360,290

Datz, S., Sundström, G., Biedermann, C. L., et al. 1995, Phys. Rev. Lett., 74, 896

Elmegreen, B. G. 1979, ApJ, 232, 739

Kulsrud, R., \& Pearce, W. P. 1969, ApJ, 156, 445

Larsson, M., Danared, H., Mowat, J. R., et al. 1993, Phys. Rev. Lett., 70, 430

McKee, C. F. 1989, ApJ, 345, 782

Millar, T. J., Farquar, P. R. A., \& Willacy, K. 1997, A\&AS, 121,139

Mouschovias, T. Ch. 1987, in Physical Processes in Interstellar Clouds, ed. G. E. Morfill, \& M. Scholer (Dordrecht, D. Reidel Publishing Company), 453

Mouschovias, T. Ch. 1991, ApJ, 373, 169

Myers, P. C., \& Lazarian, A. 1998, ApJ, 507, L157

Oppenheimer, M., \& Dalgarno, A. 1974, ApJ, 192, 29

Ruffle, D. P., Hartquist, T. W., Rawlings, J. M. C., \& Williams, D. A. 1998, A\&A, 334, 678

Ruffle, D. P., Rae, J. G. L., Pilling, M. J., Hartquist, T. W., \& Herbst, E. 2002, A\&A, 381, L13

Sundström, G., Mowat, J. R., Danared, H., et al. 1994, Science, 263, 785

Tomlin, A. S., Pilling, M. J., Turányi, T., Merkin, J. H., \& Brindley, J. 1992, Comb \& Flame, 91, 107

Tomlin, A. S., Turányi, T., \& Pilling, M. J. 1997, in Low Temperature Combustion and Autoignition, ed. M. J. Pilling (Elsevier, Amsterdam), 293

Williams, J. P., Blitz, L., \& Stark, A. A. 1995, ApJ, 451, 252 